Article

\title{
17 $\beta$-Hydroxysteroid Dehydrogenase Type 2 Expression Is Induced by Androgen Signaling in Endometrial Cancer
}

\author{
Chiaki Hashimoto ${ }^{1}$, Yasuhiro Miki ${ }^{2}$, Sota Tanaka ${ }^{1}$, Kiyoshi Takagi ${ }^{3}$, Misaki Fue ${ }^{2}$, \\ Zhulanqiqige Doe ${ }^{2}$, Bin $\mathrm{Li}^{1}{ }^{1}$, Nobuo Yaegashi ${ }^{1}$, Takashi Suzuki ${ }^{3}$ and Kiyoshi Ito ${ }^{2, *}$ \\ 1 Department of Obstetrics and Gynecology, Tohoku University Graduate School of Medicine, \\ Sendai 980-8575, Japan; chiaki@med.tohoku.ac.jp (C.H.); tanakasouta@hotmail.co.jp (S.T.); \\ reallylibin@gmail.com (B.L.); nobuo.yaegashi@gmail.com (N.Y.) \\ 2 Department of Disaster Obstetrics and Gynecology, International Research Institute of Disaster \\ Science (IRIDeS), Tohoku University, Sendai 980-8577, Japan; miki@irides.tohoku.ac.jp (Y.M.); \\ fue@med.tohoku.ac.jp (M.F.); zhulanqiqige@med.tohoku.ac.jp (Z.D.) \\ 3 Department of Pathology and Histotechnology, Tohoku University Graduate School of Medicine, \\ Sendai 980-8575, Japan; k-takagi@med.tohoku.ac.jp (K.T.); t-suzuki@patholo2.med.tohoku.ac.jp (T.S.) \\ * Correspondence: iridesdog@yahoo.co.jp; Tel./Fax: +81-22-273-6284
}

Received: 23 February 2018; Accepted: 9 April 2018; Published: 10 April 2018

check for updates

\begin{abstract}
Endometrial cancer is one of the most common female pelvic cancers and has been considered an androgen-related malignancy. Several studies have demonstrated the anti-cell proliferative effect of androgen on endometrial cancer cells; however, the mechanisms of the anti-cancer effect of androgen remain largely unclear. $17 \beta$-hydroxysteroid dehydrogenase type 2 (17 $\beta$-HSD2), which catalyzes the conversion of E2 to E1, is known to be upregulated by androgen treatment in breast cancer cells. In this study, we therefore focused on the role of androgen on estrogen dependence in endometrial cancer. Dihydrotestosterone (DHT) was found to induce $17 \beta-H S D 2$ mRNA and protein expression in HEC-1B endometrial cancer cells. DHT could also inhibit cell proliferation of HEC-1B when induced by estradiol treatment. In 19 endometrioid endometrial adenocarcinoma (EEA) tissues, intratumoral DHT concentration was measured by liquid chromatography/electrospray tandem mass spectrometry and was found to be significantly correlated with $17 \beta-H S D 2$ immunohistochemical status. We further examined the correlations between 17 $\beta$-HSD2 immunoreactivity and clinicopathological parameters in 53 EEA tissues. 17 $\beta$-HSD2 status was inversely associated with the histological grade, clinical stage, and cell proliferation marker Ki-67, and positively correlated with progesterone receptor expression. $17 \beta-H S D 2$ status tended to be positively associated with androgen receptor status. In 53 EEA cases, the $17 \beta$-HSD2-positive group tended to have better prognosis than that for the negative group with respect to progression-free survival and endometrial cancer-specific survival. These findings suggest that androgen suppresses the estrogen dependence of endometrial cancer through the induction of $17 \beta-H S D 2$ in endometrial cancer.
\end{abstract}

Keywords: $17 \beta$-hydroxysteroid dehydrogenase type 2; androgen; endometrial cancer; endometrioid endometrial adenocarcinoma

\section{Introduction}

Endometrial carcinoma is one of the most common female pelvic malignancies in developed countries and continues to show an increased incidence. In the United States alone, 60,050 new cases and 10,470 deaths were reported for endometrial carcinoma in 2016 [1]. It is well known that sex-steroid 
hormones play pivotal roles in the development of hormone-dependent carcinomas, including prostate, breast, and endometrial cancers. In the case of endometrial carcinoma, estrogen is known to play an important role in carcinoma development and progression. As previously demonstrated, excessive and/or prolonged exposure to unopposed estrogens increases the risk of endometrial carcinoma, especially the endometrioid type, also known as Type I endometrial carcinoma [2].

Furthermore, 17 $\beta$-hydroxysteroid dehydrogenase (17 $\beta$-HSD) plays an important role in determining intratumoral estrogen concentrations in both breast and endometrial cancers. $17 \beta-\mathrm{HSD}$ type $2(17 \beta-H S D 2)$ preferentially catalyzes the conversion of testosterone and estradiol (E2) to androstenedione and estrone (E1), respectively [3,4]. On the other hand, 17 $\beta$-HSD type 1 (17 $\beta$-HSD1) is responsible for the conversion of E1 to E2 [3,4]. In breast cancer, it is suggested that 17ß-HSD1 plays an important role in the intratumoral estrogen concentration. However, in endometrial cancer $17 \beta-H S D 1$ expression is either undetectable or very weak, while $17 \beta-H S D 2$ is essential for the maintenance of intratumoral estrogen concentrations [5].

Recently, 17 $\beta-H S D 2$ expression was found to be closely associated with androgen signaling through binding to the androgen receptor (AR) in breast cancer cells [6,7]. Takagi et al. [6] reported that E2-mediated proliferation in an AR-positive breast cancer cell line, T-47D, was significantly inhibited by dihydrotestosterone (DHT). E2-mediated proliferation was also associated with increased $17 \beta-H S D 2$ expression, which was induced by DHT in a dose-dependent fashion. AR expression is also found in a large majority of endometrial cancers and is associated with a good prognosis $[8,9]$. In addition, we reported that $5 \alpha$-reductase type 1 immunoreactivity was positively associated with the intratumoral level of DHT and was an independent prognostic factor in endometrial cancer [8]. However, the mechanisms of the anti-cancer effect of androgen remain largely unclear. In the present study, we therefore first examined the effect of DHT treatment on 17 $\beta$-HSD2 expression in endometrial cancer cells in vitro followed by an examination of the correlation between the expression of $17 \beta-H S D 2$ immunoreactivity and intratumoral androgen concentrations in 19 endometrioid endometrial adenocarcinoma (EEA) tissues, as measured by liquid chromatography/electrospray tandem mass spectrometry (LC-MS/MS). Furthermore, the relationship between 17 $\beta$-HSD2 expression and clinicopathological parameters, including patient outcomes, was evaluated in an additional 53 EEA patients.

\section{Results}

Expression levels of ER $\alpha, \mathrm{AR}$, and 17 $\beta$-HSD2 in endometrial cancer cell lines were examined. Expression of ER $\alpha$ and AR were detected by Western blotting (Figure 1A). Relatively high levels of $\mathrm{ER} \alpha$ protein were detected in both Ishikawa and HEC-1B cells compared to those in HEC-1A, Sawano, and RL95-2 cells (Figure 1A). AR protein expression was detected in all cell lines except for Sawano (Figure 1A). Expression of $17 \beta-H S D 2$ mRNA evaluated by qRT-PCR is shown in Figure 1B. 17 $\beta-H S D 2$ mRNA was markedly overexpressed in HEC-1A (Figure 1B). Relatively high expression levels of $17 \beta-H S D 2$ mRNA were also detected in HEC-1B compared to Ishikawa and RL95-2 cells (Figure 1B). Based on these results, we employed Ishikawa, HEC-1A, and HEC-1B cells in subsequent 17 $\beta-H S D 2$ mRNA induction assays.

\subsection{Induction of $17 \beta-H S D 2$ Expression by DHT}

$17 \beta$-HSD2 mRNA levels in Ishikawa cells were increased by more than 1.5-fold, compared to control cells, when treated with both $1 \mathrm{nM}$ and $10 \mathrm{nM}$ DHT; however, these differences were not statistically significant (Figure 1C). DHT ( $0.1 \mathrm{nM}$ and $1 \mathrm{nM})$ treatment significantly increased $17 \beta-H S D 2$ mRNA in HEC-1A $(p<0.05)$. However, estradiol did not stimulate cell proliferation in HEC-1A (data not shown). It is possible that the ER $\alpha$ was not functional because its expression level was low in HEC-1A cells when compared to Ishikawa and HEC-1B (Figure 1A).

Expression levels of $17 \beta-H S D 2$ mRNA in HEC-1B cells were increased by DHT in a dose-dependent manner, with significant differences, compared to the control, observed from $10 \mathrm{nM}$ 
$(p<0.001)$ (Figure 2A). The effect of DHT treatment on $17 \beta-H S D 2$ mRNA induction was significantly inhibited by co-treatment with $1 \mu \mathrm{M}$ bicalutamide $(p<0.001$, Figure $1 \mathrm{~A})$. Bicalutamide $(1 \mu \mathrm{M})$ alone did not significantly change 17 $\beta-H S D 2$ mRNA levels in HEC-1B cells (data not shown). In Western blot analysis, relatively high levels of $17 \beta-H S D 2$ immunoreactivity were detected in HEC-1B cells treated with $1 \mathrm{nM}$ and $10 \mathrm{nM}$ DHT. The induction of $17 \beta-H S D 2$ immunoreactivity was inhibited by $1 \mu \mathrm{M}$ bicalutamide treatment (Figure 2B).
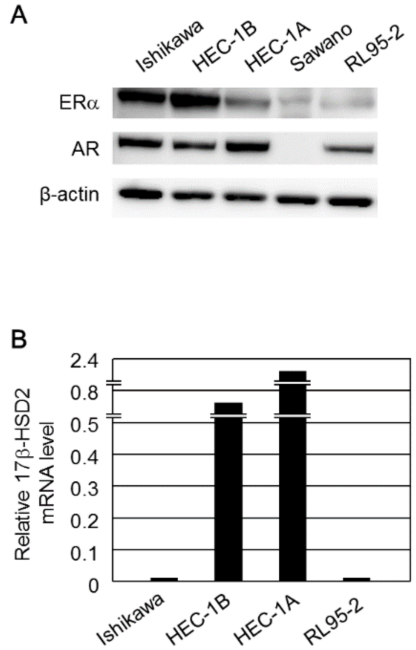

C
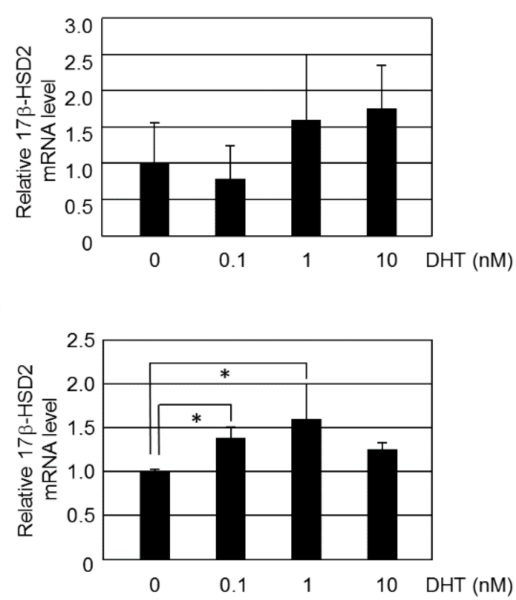

Figure 1. (A) Expression of ER $\alpha$ and AR proteins in endometrial cancer cell lines. ER $\alpha$ and AR proteins were detected by Western blotting. (B) Expression of 17 $\beta$-HSD2 mRNA in endometrial cancer cell lines. $17 \beta$-HSD 2 mRNA expression was examined using qRT-PCR. (C) Effect of DHT treatment on 17 $\beta$-HSD2 mRNA expression in Ishikawa cells; (D) effect of DHT treatment on 17 $\beta$-HSD2 mRNA expression in HEC-1A cells. ' 0 ' denotes vehicle treatment alone; ${ }^{*} p<0.05$.

A

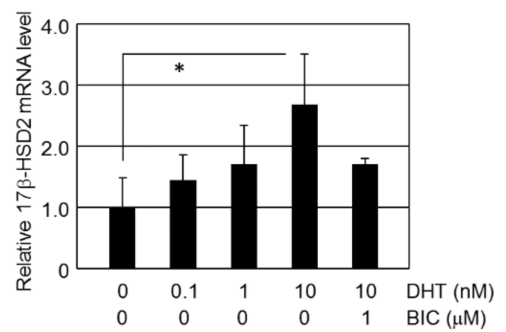

B

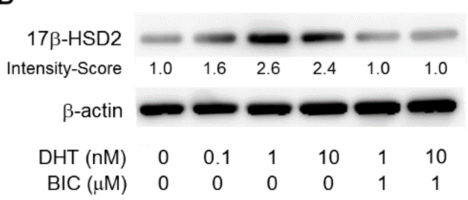

Figure 2. (A) Effect of DHT treatment on 17 $\beta$-HSD2 mRNA expression in HEC-1B cells. 17 $\beta$-HSD2 mRNA expression was examined using qRT-PCR. BIC, bicalutamide; ' 0 ' denotes vehicle treatment alone; ${ }^{*} p<0.05$. (B) Effect of DHT treatment on 17 $\beta$-HSD2 protein expression in HEC-1B cells. $17 \beta-H S D 2$ protein was detected by Western blotting. BIC, bicalutamide; ' 0 ' denotes vehicle treatment alone. (C) Effect of DHT and E2 on HEC-1B cell proliferation. BIC, bicalutamide; '0' denotes vehicle treatment alone; ${ }^{*} p<0.05 ;{ }^{* *} p<0.01$. 


\subsection{DHT Inhibits E2-Induced Cell Proliferation in HEC-1B Cells}

HEC-1B cells were treated with or without E2 $(100 \mathrm{pM})$, DHT $(10 \mathrm{nM})$, and bicalutamide $(1 \mu \mathrm{M})$ for 4 days (Figure 2C). The relative cell proliferation was evaluated as a ratio (\%) compared with control cells. HEC-1B cell proliferation was significantly higher in E2-treated (0.1 nM) HEC-1B cells than in control HEC-1B cells. DHT $(10 \mathrm{nM})$ treatment significantly inhibited the increase in HEC-1B cell proliferation induced by E2 $(0.1 \mathrm{nM})$. This DHT inhibitory effect on E2-induced cell proliferation was significantly prevented by co-treatment with bicalutamide $(1 \mu \mathrm{M})$.

\subsection{Immunohistochemistry of $17 \beta-H S D 2$ and $A R$ in EEA}

$17 \beta-H S D 2$ immunoreactivity was detected in the cytoplasm of carcinoma cells (Figure 3A), while AR immunoreactivity was detected in the nuclei of carcinoma cells (Figure 3B). In the 19 cohort 1 EEA tissues, staining for $17 \beta$-HSD2 was positive in 7 cases (36.8\%). All 19 samples were AR positive. In the 53 cohort 2 EEA tissues, staining for $17 \beta$-HSD2 was positive in 19 cases (35.8\%) (Table 1). Staining for AR was positive in 40 cases $(75.5 \%)$ (Table 1$)$.

Table 1. Correlation between $17 \beta-H S D 2$ immunoreactivity and clinicopathological parameters in 53 patients with EEA.

\begin{tabular}{|c|c|c|c|c|}
\hline \multirow{2}{*}{ Parameter } & \multirow{2}{*}{$\begin{array}{c}\text { Total } \\
(n=53)\end{array}$} & \multicolumn{3}{|c|}{ 17 $\beta$-HSD2 } \\
\hline & & $+(n=19)$ & $-(n=34)$ & $p$-Value \\
\hline Grade 1 (G1) & 22 & 11 & 11 & \\
\hline $2(\mathrm{G} 2)$ & 20 & 7 & 13 & \\
\hline $3(\mathrm{G} 3)$ & 11 & 1 & 10 & 0.0480 \\
\hline \multicolumn{5}{|l|}{ Stage } \\
\hline I, II & 43 & 19 & 24 & \\
\hline III, IV & 10 & 0 & 10 & 0.0218 \\
\hline \multicolumn{5}{|l|}{ LVI } \\
\hline No & 37 & 15 & 22 & \\
\hline Yes & 16 & 4 & 12 & 0.2704 \\
\hline \multicolumn{5}{|l|}{ MI } \\
\hline None or less than half & 31 & 14 & 17 & \\
\hline More than half & 22 & 5 & 17 & 0.0884 \\
\hline \multicolumn{5}{|l|}{ Androgen receptor } \\
\hline Positive & 40 & 17 & 23 & \\
\hline Negative & 13 & 2 & 11 & 0.0629 \\
\hline \multicolumn{5}{|l|}{ Estrogen receptor } \\
\hline Positive & 37 & 15 & 22 & \\
\hline Negative & 16 & 4 & 12 & 0.2704 \\
\hline \multicolumn{5}{|l|}{ Progesterone receptor } \\
\hline Positive & 33 & 17 & 16 & \\
\hline Negative & 20 & 2 & 18 & 0.0023 \\
\hline $\begin{array}{l}\text { Ki-67 LI median } \\
(\min -\max )(\%)\end{array}$ & & $\begin{array}{c}20.4 \\
(3-90)\end{array}$ & $\begin{array}{c}30.6 \\
(0-96)\end{array}$ & 0.0212 \\
\hline
\end{tabular}

MI, myometrial invasion; LVI, lymphovascular invasion. We performed lymphadenectomy for 42 cases, and did not resect any lymph node in 11 cases (not resected). 

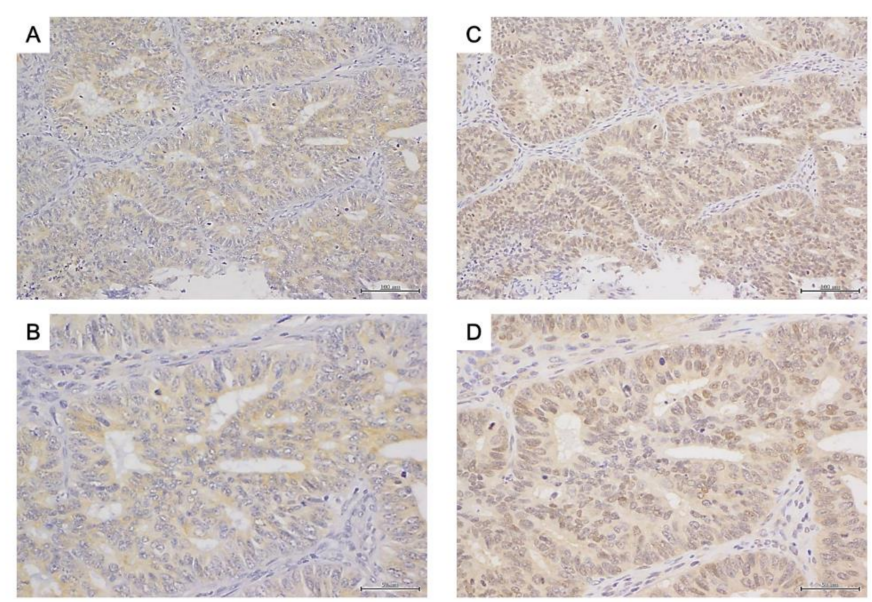

Figure 3. Immunohistochemistry for 17 $\beta$-HSD2 (endometrioid endometrial adenocarcinoma: grade 1, stage IA) ((A) low magnification; (B) high magnification) and AR (endometrioid endometrial adenocarcinoma: grade 1, stage IA) ((C) low magnification; (D) high magnification). Scale bar, $100 \mu \mathrm{m}$ $(\mathbf{A}, \mathbf{C})$ and $500 \mu \mathrm{m}(\mathbf{B}, \mathbf{D})$.

\subsection{7ß-HSD2 Expression Is Correlated with DHT Concentration in Cancer Tissues}

We evaluated the correlation between the areas of immunoreactivity of $17 \beta-\mathrm{HSD} 2$ and intratumoral DHT concentration in 19 EEA tissues (Figure 4). As shown in Figure 4A, the area of immunoreactivity of $17 \beta-\mathrm{HSD} 2(\%)$ was positively correlated with the intratumoral DHT concentration in 19 EEA tissues. We also examined the intratumoral concentration of E2 and E1 in 19 EEA tissues. As shown in Figure 4B,C, the intratumoral E2 concentration did not correlate with DHT concentration. Meanwhile, the intratumoral E1 concentration was significantly positively correlated with the intratumoral DHT concentration. However, E2/E1 ratio was not correlated with the intratumoral DHT concentration (Figure 4D).

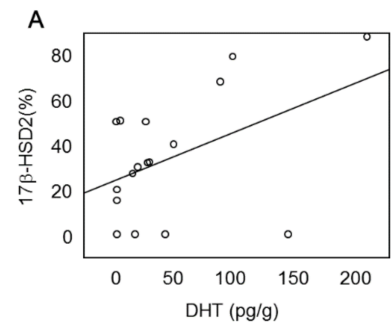

C

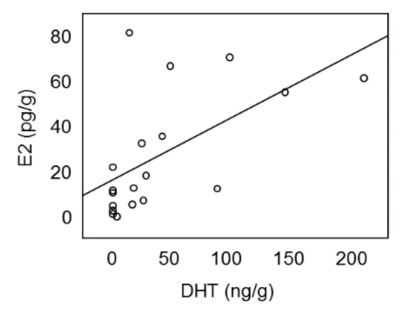

B

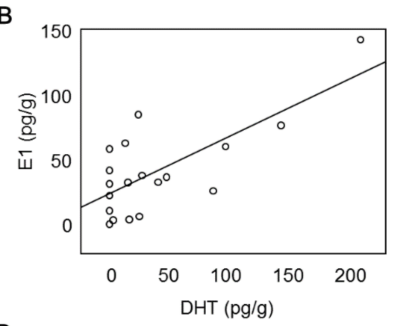

D

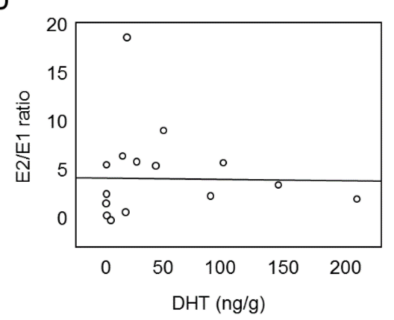

Figure 4. (A) Correlation between 17 $\beta-H S D 2(\%)$ and intratumoral DHT concentration (pg/g) in 19 endometrioid endometrial adenocarcinoma cases. (B-D) Correlation between intratumoral DHT and E1 (B), E2 (C) concentrations (pg/g) or E2/E1 ratio (D) in 19 endometrioid endometrial adenocarcinoma cases. 


\subsection{7 $\beta$-HSD2 Clinicopathological Parameters in EEA}

The correlations between $17 \beta$-HSD2 immunoreactivity and clinicopathological parameters are summarized in Table 1 . Nineteen of the 53 cohort 2 EEA tissues (35.8\%) were $17 \beta$-HSD2-positive. The $17 \beta$-HSD2 status was inversely associated with the histological grade $(p<0.05)$, clinical stage (stage I and II vs. stages III and IV), and the Ki-67 LI ( $p<0.05)$, and positively correlated with the PR LI $(p<0.01) .17 \beta-H S D 2$ status tended to be positively associated with AR status $(p=0.0629)$.

The progression-free survival (PFS) and endometrial cancer-specific survival (ECSS) curves of the patients were constructed using the Kaplan-Meier method (Figure 5). In this analysis, we examined PFS rather than disease-free survival to include stage IVB lesions, for which distant metastases remained after the primary surgery. We also examined ECSS rather than the overall survival because one patient death was unrelated to endometrial cancer and occurred in the absence of relapse. Patients positive for $17 \beta$-HSD2 immunoreactivity tended to have better prognosis than those negative for $17 \beta-H S D 2$ immunoreactivity, with respect to PFS (Figure 5A) and ECSS (Figure 5B).

A

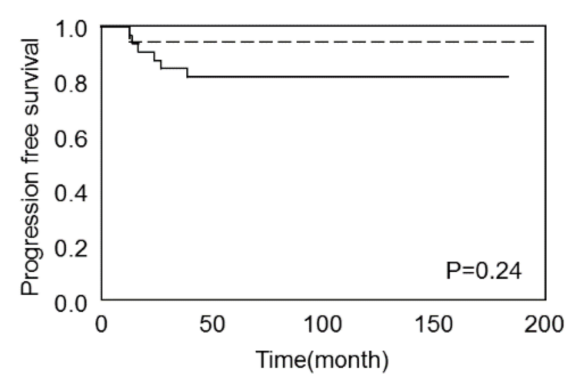

B

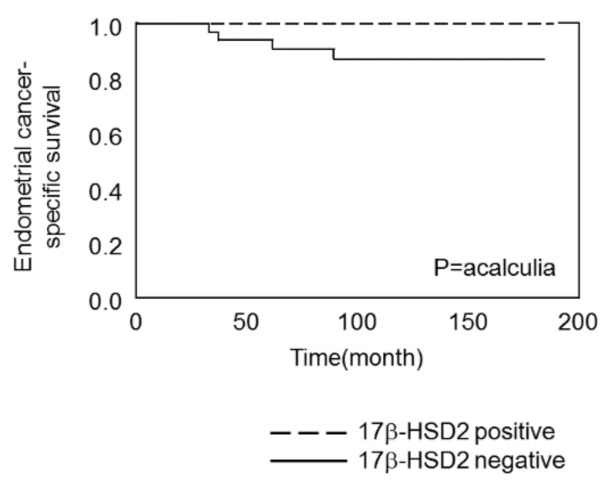

Figure 5. Correlation between $17 \beta-H S D 2$ status and progression-free survival (A) or endometrial cancer-specific survival (B) for 53 patients with endometrioid endometrial adenocarcinoma. 17 $\beta$-HSD2 status was evaluated via immunohistochemistry, and immunoreactivity greater than $50 \%$ was considered positive. Dates were compared statistically using the log-rank test. $p<0.05$ was considered significant. The median value of $17 \beta-H S D 2$ score was as follows: total, $40 \pm 20.30$ (range 0-70\%); positive group, $50 \pm 6.97$ (range $50-70 \%$ ); negative group, $20 \pm 14.45$ (range $0-40 \%$ ).

\section{Discussion}

To the best of our knowledge, this is the first report that $17 \beta-$ HSD2 was induced by DHT in endometrial cancer. It has long been known that $17 \beta-H S D 2$ mRNA expression is induced by DHT treatment in prostate (LNCaP) [10] and breast (T-47D) [6] cancer cell lines. In invasive lobular carcinoma (ILC) of the breast, significant positive association was reported between the status of androgenic

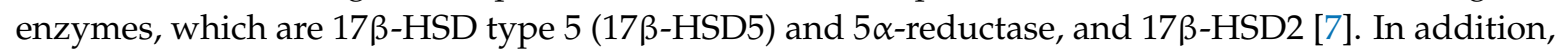
$17 \beta-H S D 2$ expression was inversely correlated with tumor size of breast ILC [7]. These findings, combined with the results from our present study, indicate that DHT acted, at least in part, through $17 \beta-H S D 2$ induction and decreasing intratumoral E2 concentrations, to influence anti-proliferative effects in breast and endometrial cancer. Takagi et al. [6] also reported that E2-mediated proliferation was significantly inhibited by DHT in AR-positive T-47D cells. In this instance, proliferation was also associated with an increase in 17 $\beta$-HSD2 expression levels [6]. In addition, local E2 concentrations were inversely associated with $17 \beta-H S D 2$ status in breast carcinoma tissues [6]. In our study, the cell proliferative effect of E2 was significantly inhibited by DHT treatment in HEC-1B cells. Therefore, it is considered that intratumoral estrogen concentrations were reduced by $17 \beta-H S D 2$, which was induced by DHT treatment in both endometrial and breast cancers. In our study, DHT did not have a significant effect on 17 $\beta$-HSD2 expression in Ishikawa cells, which had very low levels of $17 \beta-H S D 2$ 
expression. We believe that stable results were not obtained because of very low levels of $17 \beta-H S D 2$ expression in Ishikawa cells.

In the present study, an inverse correlation between intratumoral E2 and DHT was not observed in 19 EEA tissues examined owing to the small number of cases. Furthermore, both intratumoral E1 and E2 concentrations positively correlated with DHT concentration in all 19 EEA tissues. However, the E2/E1 ratio also did not correlate with DHT concentration for the 19 EEA cases. It is well-established that in breast cancer tissues, circulating androstenedione is converted by aromatase to E1 [11,12]. Intratumoral E1 is then further converted to E2 by $17 \beta-H S D 1$ activity in breast cancer tissues $[11,12]$. Therefore, androstenedione has a key role in intratumoral estrogen synthesis in estrogen-dependent breast cancer. On the other hand, in endometrial cancer, E1 is not converted to E2 because of lack of $17 \beta$-HSD1 expression [13]. As expected, there was no 17 $\beta$-HSD1 immunoreactivity in 19 EEA tissues examined in our study (data not shown). Therefore, testosterone to E2 conversion is an important pathway for intratumoral estrogen synthesis in endometrial cancer. It is also well-known that $17 \beta$-HSD2 converts testosterone into androstenedione, whereas $17 \beta$-HSD5 produces testosterone from androstenedione $[14,15]$. Therefore, these findings, in addition to the results from our study, suggest that $17 \beta-H S D 2$ is a key player in intratumoral estrogen and androgen production. Further examination of the correlation between $17 \beta-\mathrm{HSD} 2$ and other estrogen/androgen-related enzymes is, however, required to clarify the role of $17 \beta-\mathrm{HSD} 2$ in the intratumoral hormone environment of endometrial cancer.

In breast cancer, $17 \beta-H S D 2$ expression was reported to show significant association with decreased risk to develop late relapse $[16,17]$. We have reported that $17 \beta-H S D 2$ immunoreactivity was detected in $37 \%$ of endometrial carcinoma cases and correlated with $17 \beta-\mathrm{HSD} 2$ enzymatic activity and expression of $17 \beta-H S D 2$ mRNA $[13,18]$. In a normal endometrium, it was reported that both $17 \beta-H S D 2$ protein and mRNA were present at all the stages of the secretory phase, but not in the endometrial mucosa during the proliferative phase $[18,19]$. Several studies consistently detected $17 \beta-H S D 2$ mRNA expression in endometrial carcinoma compared to the adjacent normal endometrium at menopause [20-22]. Therefore, the $17 \beta-H S D 2$ enzyme may play an important role in modifying the balance of estrogen production in endometrial carcinoma. In this study, 17 $\beta-$ HSD2 status was inversely associated with the histological grade, clinical stage (stage I and II vs. stages III and IV), and the Ki-67 LI (Table 1). The $17 \beta$-HSD2 positive cases had lower levels of Ki-67 LI; therefore, $17 \beta$-HSD2 possibly inhibits cell proliferation in EEA cells. The $17 \beta-H S D 2$ positive group tended to have good prognoses, but a significant difference between them was not observed. In 17 $\beta$-HSD2 positive cases, there were no deaths. Further studies, including a larger number of cases and longer periods of follow-up, are, therefore, warranted to elucidate the functional significance of 17 $\beta$-HSD2 in endometrial cancer.

$17 \beta-H S D 2$ is considered as a DHT-induced gene in endometrial cancer cells, although androgen-responsive genes are not currently characterized in endometrial cancer cells. In the present study, DHT was found to induce 17 $\beta-H S D 2$ expression in HEC-1B cells. To the best of our knowledge, these findings have not been previously reported. Results obtained in our study suggest that the androgen signal plays a crucial role in the estrogen-dependency of ER-positive endometrial cancer cells. AR target genes such as XBP1, MYC, ZBTB16, and UHRF1 were previously reported to be induced by DHT treatment in AR-positive endometrial cancer MFE-296 cells [23]. It was also reported that XBP1 and UHRF1 are related to tumor growth or carcinogenesis in endometrial cancer $[24,25]$. Furthermore, several studies demonstrated that tumor suppressor genes were directly induced by androgen treatment through AR genomic action in breast and prostate cancers [26,27]. It has also been suggested that androgen and its receptor signal may exert anti-tumor effects on endometrial cancer $[14,15]$. Further studies, such as comprehensive gene expression analysis, are, however, required to clarify the role that androgens play in the pathogenesis of endometrial cancer. 


\section{Materials and Methods}

\subsection{EEA Patient and Tissue Preparation}

A total of 72 endometrial endometrioid adenocarcinoma tissues (EEA) of postmenopausal women were retrieved from the surgical pathology files of Tohoku University Hospital, Sendai, Japan. Both fresh-frozen and formalin-fixed paraffin-embedded (FFPE) specimens were available for 19 patients operated between 2012 and 2013 (cohort 1). The other 53 EEA tissues were available only as FFPE samples and were collected between 1993 and 2003 (cohort 2). The Ethics Committee of Tohoku University School of Medicine approved the research protocol of this examination (No. 2013-1-265). The clinicopathological parameters of the 19 patients in cohort 1 are summarized in Table S1. We measured E2, E1, and DHT concentration using LC-MS/MS in the 19 EEA fresh-frozen samples. The clinicopathological features of the 53 patients in cohort 2, for whom only FFPE tissues were available, are summarized in Table S2. None of the patients received radiation therapy, hormone therapy, or chemotherapy before surgery. All 72 EEA samples were post-menopausal to exclude the effect of serum hormonal concentration.

In Tohoku University Hospital, the standard primary treatment is surgery consisting of total abdominal hysterectomy, salpingo-oophorectomy, and pelvic and/or para-aortic lymphadenectomy with peritoneal washing cytology. Among 19 and 53 patients in cohort 1 and 2, 12 patients in cohort 1 and 42 patients in cohort 2 underwent lymphadenectomy, respectively. The lymph node metastasis was shown in four patients in cohort 1 and three patients in cohort 2, respectively. Pathological diagnosis including evaluation of pathological types and histologic grades was evaluated independently by pathologist and cytopathologist (S.T., K.I.). We diagnosed the patients according to the FIGO 2009 staging guidelines (FIGO Committee on Gynecologic Oncology, 2009).

Among 53 patients in cohort 2, 31 patients received pelvic radiation therapy (50 Gy) or 3-6 courses of chemotherapy [cisplatin-based combination regimen CAP $\left(60-70 \mathrm{mg} / \mathrm{m}^{2}\right.$ cisplatin, $40 \mathrm{mg} / \mathrm{m}^{2}$ doxorubicin, and $500 \mathrm{mg} /$ body weight cyclophosphamide, triweekly)]. Among 19 patients in cohort 1 , 10 patients received 3-6 courses of chemotherapy [AP $\left(60 \mathrm{mg} / \mathrm{m}^{2}\right.$ adriamycin and $50 \mathrm{mg} / \mathrm{m}^{2}$ cisplatin, triweekly) or TC (175 mg $/ \mathrm{m}^{2}$ Taxol and area under the curve 5 carboplatin, triweekly)] after surgery. Patients diagnosed with early-stage and low-grade disease (stage IA, grade 1; or stage IA, grade 2) did not receive any adjuvant therapy. Patients with poor performance status also had no any adjuvant therapy. None of the patients in cohorts 1 and 2 received hormonal therapy after surgery.

\subsection{Cell Lines and Chemicals}

Ishikawa 3-H-12, HEC-1A, and HEC-1B were obtained from the Japanese Collection of Research Bioresources Cell Bank, National Institutes of Biomedical Innovation, Health and Nutrition (Osaka, Japan). RL95-2 (CRL-1671) was obtained from the American Type Culture Collection (Manassas, VA, USA). Sawano was obtained from the RIKEN BioResource Center (Tsukuba, Japan). Ishikawa 3-H-12, HEC-1A, and HEC-1B were cultured in MEM (Sigma-Aldrich, St. Louis, MO, USA) with 10\% fetal bovine serum (FBS; Nichirei, Tokyo, Japan). HEC-1B cells were cultured in phenol red-free DMEM/F12 (Sigma-Aldrich) medium containing 10\% dextran-coated charcoal (DCC)-FBS for three days before experimental treatment. DHT and E2 were purchased from Wako Pure Chemical Industries (Osaka, Japan). Bicalutamide, was purchased from Abcam (Cambridge, UK). Bicalutamide, which is well established as an androgen receptor antagonist, was employed in the range of $1 \mu \mathrm{M}$ to $10 \mu \mathrm{M}$ in several in vitro studies [28-30]. $10 \mu \mathrm{M}$ bicalutamide had a cytotoxic effect at $24 \mathrm{~h}$ on HEC-1B cells (data not shown). Therefore, in this study, we used $1 \mu \mathrm{M}$ bicalutamide to block androgen receptor signals. The status of cell proliferation was determined using the WST-8 (2-[2-methoxy-4-nitrophenyl]-3-[4-nitrophenyl]-5-[2,4-disulfophenyl]-2H-tetrazolium monosodium salt) method (Cell Counting Kit-8; Dojindo, Kumamoto, Japan).

In general, the $\mathrm{E} 2$ concentration used in in vitro studies ranged from $0.1 \mathrm{nM}$ to $10 \mathrm{nM}$ [31-33]. In this study, we used $0.1 \mathrm{nM}$ E2, which was within the range of E2 levels found in EEA examined 
in this study. We used 0.1-10 nM DHT, the range used for in vitro experiments $[6,29,30]$, for the $17 \beta-H S D 2$ mRNA induction assay. A concentration of $10 \mathrm{nM}$ DHT was approximately 10 times the average intratumoral concentration in EEA examined in this study. It is considered that $10 \mathrm{nM} \mathrm{DHT}$ did not exert a significant pharmacological effect in this examination due to the following reasons: DHT may be used at doses up to $100 \mathrm{nM}$ [30]; the effect of DHT was inhibited by AR antagonist (Figure 2); and the induction of $17 \beta-H S D 2$ mRNA was also obtained by $1 \mathrm{nM}$ DHT treatment, though the difference was not statistically significant (Figure 2).

\subsection{Real-Time PCR}

Total RNA was extracted using TRIzol reagent (Molecular Research Center, Cincinnati, OH, USA), and cDNA synthesized using a QuantiTect reverse transcription kit (Qiagen, Hilden, Germany). Real-time PCR was carried out using the LightCycler System and FastStart DNA Master SYBR Green I (Roche Diagnostics, Mannheim, Germany). The PCR primer sequences for $17 \beta-H S D 2$ and the ribosomal protein L13A (RPL13A) were as follows; 17 $\beta$-HSD2 (NM_002153): forward $5^{\prime}$-CAAAGGGAGGCTGGTGAA- $3^{\prime}$ and reverse $5^{\prime}$-TTGAGGACCTCTGTGTATTT-3'; and RPL13A (NM_012423): forward 5'-CCTGGAGGAGAAGAGGAAAGAGA-3' ${ }^{\prime}$ and reverse 5'-TTGAGGACCTCTGTGTATTTGTCAA-3'. PCR products were purified and subjected to direct sequencing to verify amplification of the correct sequences. $17 \beta-H S D 2$ mRNA levels were determined as a ratio of the reference $R P L 13 A$ mRNA levels (\%). We used only one housekeeping gene for normalization of quantitative PCR.

\subsection{Western Blotting}

Protein was extracted from cultured cells using Mammalian Protein Extraction Reagent (Pierce Biotechnology, Rockford, IL, USA) added with Halt Protease Inhibitor Cocktail (Pierce Biotechnology). The protein extracted from whole cell $(20 \mu \mathrm{g})$ was analyzed by SDS-PAGE ( $10 \%$ acrylamide gel) and transferred onto Hybond P polyvinylidene difluoride membrane (GE Healthcare, Little Chalfont, UK). Primary antibodies employed in this study were anti-human 17 $\beta$-HSD2 (10978-1-AP; Proteintech, Chicago, IL, USA) and anti-human $\beta$-actin (AC-15; Sigma-Aldrich). Antibody-protein complexes were detected using ECL plus Western Blotting Detection reagents (GE Healthcare), and visualized with LAS-1000 image analyzer (Fuji Photo Film, Tokyo, Japan). The intensity of each band of 17ß-HSD2 was quantitated by using the Imaging Analyzer (Lumina Vision; MITANI CORPORATION, Tokyo, Japan). The data were demonstrated as an intensity score in Figure 2.

\subsection{Immunohistochemistry}

Rabbit polyclonal antibody against 17 $\beta$-HSD2 (10978-1-AP) was purchased from Proteintech. Mouse monoclonal antibodies against androgen receptor (AR; AR441), estrogen receptor (ER; ER1D5), progesterone receptor (PR; MAB429), and Ki-67 (MIB1) were purchased from DAKO (Carpinteria, CA, USA), Immunotech (Marseille, France), Chemicon (Temecula, CA, USA), and DAKO, respectively. A Histofine Kit (Nichirei), which employs the streptavidin-biotin amplification method, was used for immunohistochemistry. The antigen-antibody complex was visualized with 3,3'-diaminobenzidine (DAB) solution ( $1 \mathrm{mM} \mathrm{DAB}, 50 \mathrm{mM}$ Tris- $\mathrm{HCl}, \mathrm{pH} 7.6$, and $0.006 \% \mathrm{H}_{2} \mathrm{O}_{2}$ ) and counterstained with hematoxylin.

\subsection{Evaluation of Immunoreactivity}

The immune expression of AR, PR, ER, and Ki-67 was detected in the nuclei of endometrial cancer cells. We counted more than 500 carcinoma cells from at least three representative high-power fields $(\times 400)$. The percentage of immunoreactive cells [labeling index (LI)] was evaluated. LI more than $10 \%$ was evaluated as being a positive case according to previous reports [34,35]. 17 $\beta$-HSD2 immunoreactivity was detected in the cytoplasm of carcinoma cells, which were evaluated using a semi-quantitative score such as positive and negative according to previous reports $[13,18]$. 
Taking both intensity of immunoreactivity and expression areas into consideration, specimens stained with more than $50 \%$ immunoreactivity for $17 \beta-H S D 2$ were evaluated as a positive case, and those with less than $50 \%$ immunoreactivity were determined as a negative case $[13,18]$. The immunohistochemistry of $17 \beta-H S D 2$ was reported to be significantly associated with its enzyme activity and mRNA expression, when the cutoff value of the immunohistochemical score was $50 \%$ [18].

\subsection{LC-MS/MS}

The intratumoral concentrations of DHT, E2, and E1 in 19 endometrial specimens were measured using LC-MS/MS at ASKA Pharma Medical Co. Ltd. (Kawasaki, Japan), as described previously [6,36]. Approximately $1 \mathrm{~cm}^{3}$ specimens were obtained immediately after hysterectomy and cryopreserved at $-80^{\circ} \mathrm{C}$ in liquid nitrogen. Pathological diagnoses were conducted using an adjacent section of tissue. For all of these specimens we employed LC-MS/MS analysis, which confirmed that the proportion of carcinoma cells was at least $80 \%$. The weights of tissue specimens used for LC-MS/MS analysis were 9-100 mg (mean \pm standard deviation [SD]; $49 \pm 21 \mathrm{mg}$ ). Frozen tissues were homogenized in $1 \mathrm{~mL}$ distilled water. Then, the steroid fraction derived from these samples was extracted by diethyl ether. LC system (Agilent 1100, Agilent Technologies, Waldbronn, Germany) coupled with an API 4000 triple stage quadrupole mass spectrometer (Applied Biosystems, Concord, ON, Canada) operated with electron spray ionization in the positive ion mode were employed in this analysis. Chromatographic separation was performed on a Cadenza CD-C ${ }^{18}$ column $(3 \times 150 \mathrm{~mm}, 3.5 \mathrm{~mm}$, Imtakt, Kyoto, Japan). The detection limits of E2, E1, and DHT were 1.0. 2.0, 1.0 pg/g, respectively. Values less than the detection limit were assigned $0.0 \mathrm{pg} / \mathrm{g}$.

\subsection{Statistical Analyses}

Statistical analyses were carried out using JMP Pro12 (SAS Institute Japan, Tokyo, Japan). The statistical significance of correlations between the 17 $\beta$-HSD2 status and the DHT concentration in EEA were examined using the Wilcoxon test. The statistical significance of correlations between $17 \beta-H S D 2$ status and other clinicopathological parameters [grade, stage, lymphovascular invasion (LVI), myometrial invasion (MI), AR status, ER status, PR status, and Ki-67 labeling index (LI)] were examined using the $\chi^{2}$ and Wilcoxon tests. Univariate analyses were examined using the Kaplan-Meier method and the log-rank test. $p$-values $<0.05$ were considered statistically significant in this study.

\section{Conclusions}

E2 is known as a major substrate for $17 \beta-H S D 2.17 \beta-H S D 2$ catalyzes the oxidation of the highly active E2 into the weak estrone, which has a very low affinity to ER compared to E2. In our study, HEC-1B cell proliferation was increased by E2 treatment. We found that induction of 17 $\beta$-HSD2 occurred in HEC-1B cells when the cells were treated with DHT with E2, and E2 co-treated was converted into the weaker form, E1 (Figure 6). This finding suggests that DHT decreased E2-dependent endometrial cancer proliferation. 


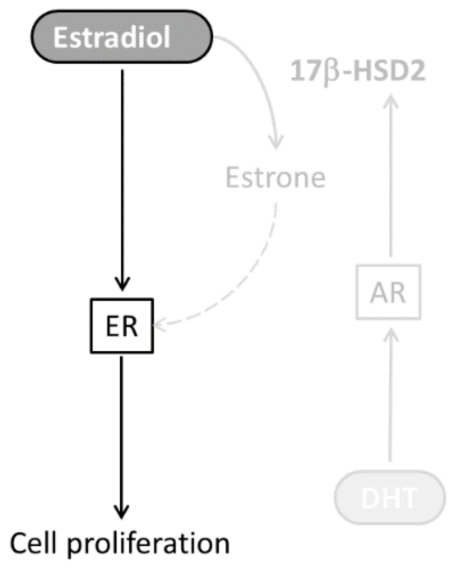

B

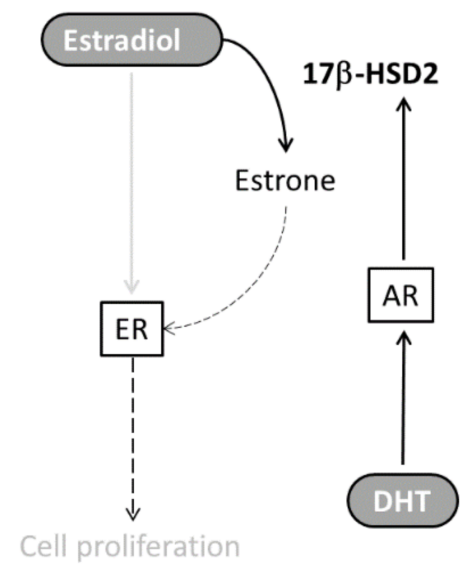

Figure 6. (A) In endometrial cancer cells, estradiol promotes cancer cell proliferation through binding to estrogen receptors (ER). (B) Androgen [dihydrotestosterone (DHT)] induces 17 $\beta$-HSD2 expression through binding to androgen receptors (AR). When estradiol is converted into the weaker estrone, by $17 \beta-H S D 2$, the cell proliferative activity of ER signal is diminished.

Supplementary Materials: The following are available online at http:/ /www.mdpi.com/1422-0067/19/4/1139/ s1.

Acknowledgments: This research was partially supported by JSPS KAKENHI Grant no. 15K08338 (Tokyo, Japan) and the Yamaguchi Endocrine Research Foundation (Tokyo, Japan).

Author Contributions: Chiaki Hashimoto and Yasuhiro Miki designed the study and wrote the initial draft of the manuscript. Chiaki Hashimoto performed the experiments and analyzed the data. Zhulanqiqige Doe and Misaki Fue provided technical assistances regarding immunohistochemistry. Misaki Fue and Bin Li provided technical assistance regarding PCR and Western blotting. Sota Tanaka, Kiyoshi Takagi, and Takashi Suzuki supervised the interpretation of histology and immunohistochemistry. Kiyoshi Ito provided crucial suggestions regarding the hormone biology of endometrial cancer. Sota Tanaka supervised the interpretation of clinical data. Kiyoshi Ito and Nobuo Yaegashi supervised all experiments and edited the manuscript.

Conflicts of Interest: The authors declare no conflict of interest.

\section{References}

1. Siegel, R.L.; Miller, K.D.; Jemal, A. 2016 Cancer statistics. CA A Cancer J. Clin. 2016, 66, 7-30. [CrossRef] [PubMed]

2. Bokhman, J.V. Two pathogenetic types of endometrial carcinoma. Gynecol. Oncol. 1983, 15, 10-17. [CrossRef]

3. Wu, L.; Einstein, M.; Geissler, W.M.; Chan, H.K.; Elliston, K.O.; Andersson, S. Expression cloning and characterization of human 17 beta-hydroxysteroid dehydrogenase type 2, a microsomal enzyme possessing 20 alpha-hydroxysteroid dehydrogenase activity. J. Biol. Chem. 1993, 268, 12964-12969. [PubMed]

4. $\quad$ Engeli, R.T.; Rohrer, S.R.; Vuorinen, A.; Herdlinger, S.; Kaserer, T.; Leugger, S.; Schuster, D.; Odermatt, A. Interference of Paraben Compounds with Estrogen Metabolism by Inhibition of $17 \beta$-Hydroxysteroid Dehydrogenases. Int. J. Mol. Sci. 2017, 18, 2007. [CrossRef] [PubMed]

5. Ito, K.; Utsunomiya, H.; Niikura, H.; Yaegashi, N.; Sasano, H. Inhibition of estrogen actions in human gynecological malignancies: New aspects of endocrine therapy for endometrial cancer and ovarian cancer. Mol. Cell Endocrinol. 2011, 340, 161-167. [CrossRef] [PubMed]

6. Takagi, K.; Miki, Y.; Nagasaki, S.; Hirakawa, H.; Onodera, Y.; Akahira, J.; Ishida, T.; Watanabe, M.; Kimijima, I.; Hayashi, S.; et al. Increased intratumoral androgens in human breast carcinoma following aromatase inhibitor exemestane treatment. Endocr. Relat. Cancer 2010, 17, 415-430. [CrossRef] [PubMed]

7. Yoda, T.; McNamara, K.M.; Miki, Y.; Takagi, M.; Rai, Y.; Ohi, Y.; Sagara, Y.; Tamaki, K.; Hirakawa, H.; Ishida, T.; et al. Intratumoral androgen metabolism and actions in invasive lobular carcinoma of the breast. Cancer Sci. 2014, 105, 1503-1509. [CrossRef] [PubMed] 
8. Tanaka, S.; Miki, Y.; Hashimoto, C.; Takagi, K.; Zhulanqiqige, D.; Li, B.; Yaegashi, N.; Suzuki, T.; Ito, K. The role of $5 \alpha$-reductase type 1 associated with intratumoral dihydrotestosterone concentrations in human endometrial carcinoma. Mol. Cell Endocr. 2015, 401, 56-64. [CrossRef] [PubMed]

9. Kamal, A.M.; Bulmer, J.N.; DeCruze, S.B.; Stringfellow, H.F.; Martin-Hirsch, P.; Hapangama, D.K. Androgen receptors are acquired by healthy postmenopausal endometrial epithelium and their subsequent loss in endometrial cancer is associated with poor survival. Br. J. Cancer 2016, 114, 688-696. [CrossRef] [PubMed]

10. Wang, J.H.; Tuohimaa, P. Regulation of $17 \beta$-hydroxysteroid dehydrogenase type 2, type 4 and type 5 by calcitriol, LXR agonist and 5alpha-dihydrotestosterone in human prostate cancer cells. J. Steroid Biochem. Mol. Biol. 2007, 107, 100-105. [CrossRef] [PubMed]

11. Sasano, H.; Suzuki, T.; Miki, Y.; Moriya, T. Intracrinology of estrogens and androgens in breast carcinoma. J. Steroid Biochem. Mol. Biol. 2008, 108, 181-185. [CrossRef] [PubMed]

12. Miki, Y.; Suzuki, T.; Sasano, H. Intracrinology of sex steroids in ductal carcinoma in situ (DCIS) of human breast: Comparison to invasive ductal carcinoma (IDC) and non-neoplastic breast. J. Steroid Biochem. Mol. Biol. 2009, 114, 68-71. [CrossRef] [PubMed]

13. Ito, K.; Utsunomiya, H.; Suzuki, T.; Saitou, S.; Akahira, J.; Okamura, K.; Yaegashi, N.; Sasano, H. $17 \beta$-hydroxysteroid dehydrogenases in human endometrium and its disorders. Mol. Cell Endocrinol. 2006, 248, 136-140. [CrossRef] [PubMed]

14. Miki, Y.; Fue, M.; Takagi, K.; Hashimoto, C.; Tanaka, S.; Suzuki, T.; Ito, K. Androgen receptor and intracrine androgen signaling in endometrial carcinomas. Recept. Clin. Investig. 2015, 2, e853.

15. Ito, K.; Miki, Y.; Suzuki, T.; McNamara, K.M.; Sasano, H. In situ androgen and estrogen biosynthesis in endometrial cancer: Focus on androgen actions and intratumoral production. Endocr. Relat. Cancer 2016, 23, R323-R335. [CrossRef] [PubMed]

16. Gunnarsson, C.; Olsson, B.M.; Stål, O. Southeast Sweden Breast Cancer Group, Abnormal expression of 17beta-hydroxysteroid dehydrogenases in breast cancer predicts late recurrence. Cancer Res. 2001, 61, 8448-8451. [PubMed]

17. Gunnarsson, C.; Hellqvist, E.; Stål, O. 17beta-Hydroxysteroid dehydrogenases involved in local oestrogen synthesis have prognostic significance in breast cancer. Br. J. Cancer 2005, 92, 547-552. [CrossRef] [PubMed]

18. Utsunomiya, H.; Suzuki, T.; Kaneko, C.; Takeyama, J.; Nakamura, J.; Kimura, K.; Yoshihama, M.; Harada, N.; Ito, K.; Konno, R.; et al. The analyses of 17beta-hydroxysteroid dehydrogenase isozymes in human endometrial hyperplasia and carcinoma. J. Clin. Endocrinol. Metab. 2001, 86, 3436-3443. [PubMed]

19. Mustonen, M.V.; Isomaa, V.V.; Vaskivuo, T.; Tapanainen, J.; Poutanen, M.H.; Stenbäck, F.; Vihko, R.K.; Vihko, P.T. Human 17beta-hydroxysteroid dehydrogenase type 2 messenger ribonucleic acid expression and localization in term placenta and in endometrium during the menstrual cycle. J. Clin. Endocrinol. Metab. 1998, 83, 1319-1324. [PubMed]

20. Lépine, J.; Audet-Walsh, E.; Grégoire, J.; Têtu, B.; Plante, M.; Ménard, V.; Ayotte, P.; Brisson, J.; Caron, P.; Villeneuve, L.; et al. Circulating estrogens in endometrial cancer cases and their relationship with tissular expression of key estrogen biosynthesis and metabolic pathways. J. Clin. Endocrinol. Metab. 2010, 95, 2689-2698. [CrossRef] [PubMed]

21. Cornel, K.M.; Kruitwagen, R.F.; Delvoux, B.; Visconti, L.; Van de Vijver, K.K.; Day, J.M.; Van Gorp, T.; Hermans, R.J.; Dunselman, G.A.; Romano, A. Overexpression of $17 \beta$-hydroxysteroid dehydrogenase type 1 increases the exposure of endometrial cancer to 17ß-estradiol. J. Clin. Endocrinol. Metab. 2012, 97, E591-E601. [CrossRef] [PubMed]

22. Sinreih, M.; Hevir, N.; Rižner, T.L. Altered expression of genes involved in progesterone biosynthesis, metabolism and action in endometrial cancer. Chem. Biol. Interact. 2013, 202, 210-217. [CrossRef] [PubMed]

23. Qiu, M.; Bao, W.; Wang, J.; Yang, T.; He, X.; Liao, Y.; Wan, X. FOXA1 promotes tumor cell proliferation through AR involving the Notch pathway in endometrial cancer. BMC Cancer 2014, 14, 78. [CrossRef] [PubMed]

24. Sengupta, S.; Sharma, C.G.; Jordan, V.C. Estrogen regulation of X-box binding protein-1 and its role in estrogen induced growth of breast and endometrial cancer cells. Horm. Mol. Biol. Clin. Investig. 2010, 2, 235-243. [CrossRef] [PubMed] 
25. Sheng, Y.; Wang, H.; Liu, D.; Zhang, C.; Deng, Y.; Yang, F.; Zhang, C. Methylation of tumor suppressor gene CDH13 and SHP1 promoters and their epigenetic regulation by the UHRF1/PRMT5 complex in endometrial carcinoma. Gynecol. Oncol. 2016, 140, 145-151. [CrossRef] [PubMed]

26. Wang, Y.; He, X.; Yu, Q.; Eng, C. Androgen receptor-induced tumor suppressor, KLLN, inhibits breast cancer growth and transcriptionally activates p53/p73-mediated apoptosis in breast carcinomas. Hum. Mol. Genet. 2013, 22, 2263-2272. [CrossRef] [PubMed]

27. Geng, C.; Rajapakshe, K.; Shah, S.S.; Shou, J.; Eedunuri, V.K.; Foley, C.; Bond, R. Androgen receptor is the key transcriptional mediator of the tumor suppressor SPOP in prostate cancer. Cancer Res. 2014, 74, 5631-5643. [CrossRef] [PubMed]

28. Robinson, J.L.; Macarthur, S.; Ross-Innes, C.S.; Tilley, W.D.; Neal, D.E.; Mills, I.G.; Carroll, J.S. Androgen receptor driven transcription in molecular apocrine breast cancer is mediated by FoxA1. EMBO J. 2011, 30, 3019-3027. [CrossRef] [PubMed]

29. Cochrane, D.R.; Bernales, S.; Jacobsen, B.M.; Cittelly, D.M.; Howe, E.N.; D'Amato, N.C.; Spoelstra, N.S.; Edgerton, S.M.; Jean, A.; Guerrero, J.; et al. Role of the androgen receptor in breast cancer and preclinical analysis of enzalutamide. Breast Cancer Res. 2014, 16, R7. [CrossRef] [PubMed]

30. Zhu, A.; Li, Y.; Song, W.; Xu, Y.; Yang, F.; Zhang, W.; Yin, Y.; Guan, X. Antiproliferative Effect of Androgen Receptor Inhibition in Mesenchymal Stem-Like Triple-Negative Breast Cancer. Cell Physiol. Biochem. 2016, 38, 1003-1014. [CrossRef] [PubMed]

31. Boostanfar, R.; Amezcua, C.A.; Tourgeman, D.E.; Roy, S.; Felix, J.C.; Stanczyk, F.Z. Growth effects of raloxifene, estradiol, medroxy-progesterone acetate, and progesterone on human endometrial adenocarcinoma cells. Fertil. Steril. 2003, 79, 223-225. [CrossRef]

32. Ray, S.; Johnston, R.; Campbell, D.C.; Nugent, S.; McDade, S.S.; Waugh, D.; Panov, K.I. Androgens and estrogens stimulate ribosome biogenesis in prostate and breast cancer cells in receptor dependent manner. Gene 2013, 526, 46-53. [CrossRef] [PubMed]

33. Hamada, T.; Souda, M.; Yoshimura, T.; Sasaguri, S.; Hatanaka, K.; Tasaki, T.; Yoshioka, T.; Ohi, Y.; Yamada, S.; Tsutsui, M.; et al. Anti-apoptotic effects of PCP4/PEP19 in human breast cancer cell lines: A novel oncotarget. Oncotarget 2014, 5, 6076-6086. [CrossRef] [PubMed]

34. Saito, S.; Ito, K.; Nagase, S.; Suzuki, T.; Akahira, J.; Okamura, K.; Yaegashi, N.; Sasano, H. Progesterone receptor isoforms as a prognostic marker in human endometrial carcinoma. Cancer Sci. 2006, 97, 1308-1314. [CrossRef] [PubMed]

35. Suzuki, T.; Miki, Y.; Moriya, T.; Akahira, J.; Ishida, T.; Hirakawa, H.; Yamaguchi, Y.; Hayashi, S.; Sasano, H. 5alpha-Reductase type 1 and aromatase in breast carcinoma as regulators of in situ androgen production. Int. J. Cancer 2007, 120, 285-291. [CrossRef] [PubMed]

36. Miki, Y.; Suzuki, T.; Tazawa, C.; Yamaguchi, Y.; Kitada, K.; Honma, S.; Moriya, T.; Hirakawa, H.; Evans, D.B.; Hayashi, S.; et al. Aromatase localization in human breast cancer tissues: Possible interactions between intratumoral stromal and parenchymal cells. Cancer Res. 2007, 67, 3945-3954. [CrossRef] [PubMed]

(C) 2018 by the authors. Licensee MDPI, Basel, Switzerland. This article is an open access article distributed under the terms and conditions of the Creative Commons Attribution (CC BY) license (http://creativecommons.org/licenses/by/4.0/). 